\title{
SPATIAL PRODUCTIVITY SPILLOVERS \\ FROM PUBLIC INFRASTRUCTURE: \\ EVIDENCE FROM STATE HIGHWAYS
}

Douglas Holtz-Eakin

Amy Ellen Schwartz

Working Paper No. 5004

\section{NATIONAL BUREAU OF ECONOMIC RESEARCH \\ 1050 Massachusetts Avenue \\ Cambridge, MA 02138 \\ February 1995}

We thank Karin D'Agostino, Esther Gray, and Ann Wicks for their help in preparing the manuscript. John Capeci, Harry Kelejian, Jack Mintz, Dennis Robinson, Gerald Whitney, and two anonymous referees provided valuable comments on earlier drafts of the paper. This paper is part of NBER's research program in Public Economics. Any opinions expressed are those of the authors and not those of the National Bureau of Economic Research.

(C) 1995 by Douglas Holtz-Eakin and Amy Ellen Schwartz. All rights reserved. Short sections of text, not to exceed two paragraphs, may be quoted without explicit permission provided that full credit, including $\odot$ notice, is given to the source. 


\title{
SPATIAL PRODUCTIVITY SPILLOVERS \\ FROM PUBLIC INFRASTRUCTURE: \\ EVIDENCE FROM STATE HIGHWAYS
}

\begin{abstract}
Is public sector infrastructure a key determinant of productivity? Traditional, projectbased analyses of benefits and costs typically do not find large rates of return. Proponents of infrastructure spending instead point to regression-based analyses of the links between private productivity and public infrastructure that imply large productivity effects from public spending. The disparity in estimated returns is often attributed to geographic spillovers in productivity benefits that are not captured by disaggregated analyses.

We examine the degree to which state highways provide productivity benefits beyond the narrow confines of each state's borders. Despite the fact that state highways -- especially the interstate highway system -- are designed at least in part with interstate linkages in mind, we find no evidence of quantitatively important productivity spillovers.
\end{abstract}

Douglas Holtz-Eakin

Center for Policy Research

426 Eggers Hall

Syracuse University

Syracuse, NY 13244-1090

and NBER
Amy Ellen Schwartz

Wagner School of Public Service 4 Washington Square North

New York University

New York, NY 10003 


\section{INTRODUCTION}

Is public sector infrastructure a key determinant of productivity? Politicians and researchers alike have in recent years debated the efficacy of new spending on public works in order to raise productivity growth. In part, the debate hinges on issues in research methods. Traditional, project-based analyses of benefits and costs typically do not find large rates of return for new projects, while regression-based analyses of the links between private productivity and the stock of public infrastructure have implied large productivity returns to public spending. Further, in regression studies the estimated benefits appear larger in aggregate analyses than in disaggregated studies (see, e.g., Aschauer [1989] or Munnell [1990a,1990b]). Proponents of increased spending argue the disparity reflects geographic spillovers in productivity benefits that are not captured by highly disaggregated analyses:

"As the geographic focus narrows, the estimated impact of public capital becomes smaller. The most obvious explanation is that, because of leakages, one cannot capture all of the payoff to an infrastructure investment by looking at a small geographic area." (Munnell [1992], pages 193-194).

To date, however, no research has targeted specifically the spillover hypothesis. ${ }^{2}$ Hence, the purpose of this short note is to examine the degree to which state highways provide productivity benefits beyond the narrow confines of each state's borders.

State highways are a natural focus for such a test. ${ }^{3}$ While local roads in some cases cross state borders, state highways - especially the interstate highway system — are designed at least in part with interstate linkages in mind. Hence, to the extent that expansions in the road infrastructure increase productivity in neighboring states, one would expect this effect to be most dramatic for state highway investments. 
Despite this, and to anticipate the outcome, we find no evidence of quantitatively important productivity spillovers. Indeed, our estimates are consistent with the absence of dramatic productivity effects found elsewhere in the literature. The remainder of the paper is organized as follows. The following section describes the conceptual framework for our analysis. In Section 3, we discuss data and econometric issues. Section 4 contains the results of our empirical analyses. The final section is a summary with suggestions for further work in this area.

\section{CONCEPTUAL FRAMEWORK}

The starting point for our discussion is an aggregate, state-level production function for private output. Consistent with much of the recent literature and with an eye toward the empirical work to follow, we adopt the log-linear specification:

$$
y_{s}=\beta_{0}+\beta_{1} l_{s}+\beta_{2} k_{s}+\beta_{3} h_{s}^{e}+\varepsilon_{s},
$$

where $y_{s}$ is private output, $l_{s}$ is inputs of private labor, $k_{s}$ is inputs of private capital and $\varepsilon_{s}$ is a stochastic disturbance term. ${ }^{4}$ All variables are measured in natural logarithms and the subscript $s$ denotes states. The final variable in equation (2.1) is the "effective" stock of state road and highway capital, $h_{s}^{e}$. The heart of the notion of productivity spillovers is that the effective stock of capital in each state differs from the physical stock of roads and highways within that state's borders. That is, access to the roads and highways in other states contributes to the effective stock of public-sector inputs, causing the effective stock to exceed the stock physically within the state's borders. To gauge these effects, let $\delta$ measure the degree to which there are crossstate spillovers in highway capital. Specifically, let the effective capital stock of a state (state $s$ ) be related to the effective capital of a neighboring state (state $n$ ) according to: 


$$
h_{s}{ }^{e}=h_{s}+\delta h_{n}{ }^{e},
$$

where $h_{s}$ is the physical stock of highways in state $s$. If there are no interstate spillovers, $\delta=0$ and the effective and actual highway measures will coincide $\left(h_{s}^{e}=h_{s}\right)$. To the extent that $\delta$ exceeds zero, the effective highway stock rises above that physically present in the state. In the extreme, $\delta=1$ would indicate that all of the neighboring state's effective capital spills over to contribute to the effective highway stock of state $s$.

Equation (2.2) assumes that there is only one state neighboring state $s$. More generally, state $s$ may have more than one neighbor. If so, each will contribute to the effective capital stock, viz.:

$$
h_{s}^{e}=h_{s}+\delta \sum_{n=1}^{N_{s}} w_{n} h_{n}^{e},
$$

where $N_{s}$ is the number of states bordering state $s$ and $w_{n}$ is the weight attached to the effective highway capital in state $n$. Equation (2.3) may be viewed as a "production function" in which own-state highways and neighboring-state effective highways combine to produce effective highway capital in each state. We experiment below with alternative specifications of the weights in equation (2.3).

An implication of our specification is that the provision of highways in any state, say $s$, will contribute to effective capital not only in state $s$ and in any state $n$ that neighbors state $s$, but also to the effective highway capital in neighbors of state $n$, and so forth for subsequent neighbors. From this perspective, one may think of $\delta$ as measuring the rate at which the productivity effects of highway capital decay across states. Effective highway capital in directly adjacent states augments state $s$ highway capital at the rate $\delta$, the "ring" of states bordering these states contributes $\delta^{2}$, the subsequent ring contributes $\delta^{3}$, and so on. Thus, high 
values of $\delta$ indicate slow decay, and low values of $\delta$ indicate rapid decay of the productivity spillover. ${ }^{5}$

We do not observe directly the effective stocks. To draw out the implications for observable quantities, let $h$ denote the ( $N \times 1)$ vector of highway capital stocks for the states. Defining other vectors similarly, the effective capital stocks may be expressed as:

$$
h^{e}=h+\delta W h^{e},
$$

where $W$ is an $N \mathrm{x} N$ "neighbors" matrix containing weights for each state's highway capital. In the simplest case of equal weights, the entry in row $s$ and column $j$ of $W$ is equal to one if state $j$ is a neighbor to state $s$, and zero otherwise. Solving equation (2.4) for $h^{e}$ yields:

$$
h^{e}=(I-\delta W)^{-1} h,
$$

or,

$$
h^{e}=P(\boldsymbol{\delta}) h .
$$

where $P(\delta) \equiv(I-\delta W)^{-1}$. As equation (2.6) makes clear, to the extent that $\delta>0$ (i.e., there are productive spillovers) the effective stock of highways and roads in any state is determined by the actual stock of highways and roads in all the states. Further, the logic of productive spillovers is that this network should contribute to the output or productivity of state $s$. Thus, substituting (2.6) into the production function yields:

$$
y=\beta_{0}+\beta_{1} l+\beta_{2} k+\beta_{3} P(\delta) h+\varepsilon .
$$

Note that in equation (2.7), which is the centerpiece of our empirical analysis, the stock of state highway capital in state $s, h_{s}$, may affect output in every state. In this way, significant spillovers have the potential to produce a large disparity between benefits in the aggregate, and benefits measured on a state-by-state basis. 


\section{DATA AND ECONOMETRIC ISSUES}

\subsection{Data}

We estimate the spillover effects using state-by-state data for private sector output, labor, capital, and state government highway capital for the 48 contiguous states over the years 1969 to 1986. (Sample statistics for the data are shown in Table 3.1.) Output is measured by the Bureau of Economic Analysis (BEA) state-by-state series on Gross State Product. Estimates of private sector capital are from Munnell [1990]. ${ }^{6}$ Labor inputs are BEA measurements of full-time and part-time wage and salary employees.

Our measure of highway capital is the stock of state government highways in each state. ${ }^{7}$ Data are also available for the stock of roads and highways of local governments in each state, but state government roads tend to be the major roads and interstate highways for which spillover effects are likely to be present. Thus, one would not expect local roads to have the effects outlined above. In any event, we experimented with estimates using local roads and highways. These results do not change the basic nature of our results. ${ }^{8}$ We focus on the state government data in what follows.

\subsection{Econometric Issues}

We devote considerable attention to the specification of the error structure in equation (2.7). To begin, we control for business cycles and other nationwide output fluctuations through the use of year-specific intercepts. In addition, Holtz-Eakin [forthcoming] demonstrates the importance of controlling for heterogeneity through the use of state-specific effects, because more productive states have greater ability to make capital outlays. As a result, cross-sectional heterogeneity in productivity will generate variation in highway capital. 
In the presence of this reverse causality, ordinary least squares will yield inconsistent estimates of the parameters. Thus, our basic estimating equation is specified as:

$$
y_{t}=\beta_{1} l_{t}+\beta_{2} k_{t}+\beta_{3} P(\delta) h_{t}+\gamma_{t}+f+\mu_{t}
$$

where $t$ indexes years, $\mu_{t}$ is a vector of i.i.d. disturbance terms, $\gamma_{t}$ is a vector of year-specific intercepts, and $f$ is a vector of state-specific productivity differences. Importantly, the statespecific effects are time-invariant, capturing the effects of location, climate, mineral endowments, and so forth.

A standard method to control for the state effects is through the use of state dummy variables or, equivalently, by transforming the data into deviations from state means. In doing so, the source of variation that identifies the parameters is year-to-year fluctuations above or below each state's average. Because highway capital stocks accumulate slowly, such shortterm variation is quite noisy and will likely provide a misleading picture of the long-run relationships in which we are interested.

As an alternative, consider differencing the data by subtracting from equation (3.1) the comparable equation for an earlier time period. Indeed, the difference that will most likely capture long-run effects is to subtract the equation for the first year $(t=0)$ from that for the last year $(t=T)$ :

$$
y_{T}-y_{0}=\beta_{1}\left(l_{T}-l_{0}\right)+\beta_{2}\left(k_{T}-k_{0}\right)+\beta_{3} P(\delta)\left(h_{T}-h_{0}\right)+\left(\gamma_{T}-\gamma_{0}\right)+\mu_{T}-\mu_{0} .
$$

As indicated by the absence of $f$ from equation (3.2), the use of long-differences eliminates the state-specific effects. It also identifies the parameters by comparing the cumulative growth of inputs with the cumulative growth of output, exactly the sort of variation that is desirable. However, equation (3.2) amounts to a single cross-section regression of growth in output on growth in inputs. Access to panel data permits one to estimate an equation of the type in 
equation (3.2) for each year $t=T, t=T-1, t=T-2, \ldots, t=1$. Notice, however, that such an equation for $t=1$ identifies the parameters using precisely the short-term variation that we seek to avoid. Hence, we restrict our analysis to $t \geq 6$, or the years 1975 through 1986 .

Of course, rather than estimating the equation for each year separately, we may pool the differenced equations for each year, and hence exploit all of the information in our panel data in identifying the parameters. Thus, our equations use information on long-differences from 1975 to 1986 in which the data for each year is entered as differences from the initial year, 1969.

Examination of equation (3.2) reveals that the use of differences carries a cost as well - the differenced error terms $\mu_{t}-\mu_{0}$ in our pooled sample will be serially correlated. In the absence of a correction for this feature, the parameter estimates will be inefficient. However, the nature of the long-differences dictates that the structure of the covariances is quite simple. Specifically, the covariance between the error terms for $t$ and $r$ is given by

$$
E\left(\mu_{s t}-\mu_{s 0}\right)\left(\mu_{s r}-\mu_{s 0}\right)= \begin{cases}2 \sigma_{\mu}^{2}, & \text { if } t=r \\ \sigma_{\mu}^{2}, & \text { if } t \neq r\end{cases}
$$

We assume that the $\mu_{s t}$ follow a normal distribution and use this information on the error structure to yield efficient estimates. Due to the presence of $\delta$ embedded in equation (3.2), our equations are non-linear in the parameters. Hence, we estimate the parameters using nonlinear, maximum-likelihood methods.

Our discussion of state-specific effects and differencing has been motivated by the need to guard against a particular type of endogeneity bias: higher productivity states (hence, higher income states) may spend more on highways, leading to a greater stock of highways. Notice, 
however, that state-effects will control for a wide array of cross-sectional heterogeneity. For example, to the extent that interjurisdictional competition induces one state to consistently spend more on highways than a comparable state, this will be captured by the state-specific effect.

Our equations also include year-specific effects. As noted above, their inclusion is primarily motivated by the need to control for business cycle and other year-to-year fluctuations. As with state effects, however, year effects will simultaneously capture many phenomena: the effects of Federal government grant matching rates, Federal income tax policy that influences the net cost of state fiscal actions, or any other policy action that affects states and their residents in a uniform manner.

Of course, the possibility remains that movements in state output over time at a rate faster or slower than the national average will cause growth in state highways to be greater or lower than typical in the nation. While the link between annual spending flows and the cumulative highway stocks may be weak, the potential for simultaneity bias remains. In the absence of a structural model of state spending policy, we tested whether growth in private output Granger-caused growth in highway capital stocks. Specifically, using the procedures of Holtz-Eakin, Newey, and Rosen [1988] we specified a vector autoregression containing four lags each of output growth and growth of the highway stock and could not reject the null hypothesis that the coefficients on output growth equal zero in the equation for growth in highway capital. ${ }^{9}$ Thus, the primary channel of causality does not appear to run from productivity to highway capital. 
Although not conclusive, these results give us some confidence that the remainder of the analysis is not greatly contaminated by bias due to the simultaneous determination of output and the highway stock.

\section{4. $\quad$ RESULTS}

Table 4.1 presents the results of some preliminary regressions using our data. Begin with the results in panel (a) in which the data are entered as levels, as opposed to long differences, of logarithms and, thus, fail to control for state effects. The first column presents the estimates of a basic production function that ignores the potential for spillover effects in state highways. The estimated coefficients on private labor $(0.61)$ and private capital $(0.41)$ are consistent with other production function studies, and precisely estimated. The coefficient on own-state highways is 0.05 and statistically significant as well. Thus, these estimates are typical of those supporting a significant role for infrastructure investment in productivity growth.

The remainder of the columns, however, demonstrate that spillovers evidently have little to do with estimates of this type. In columns (2) through (4) we augment our basic production function with alternative measures of "neighbors" highways. ${ }^{10}$ In column (2) we measure neighbors' capital for each state as the sum of the state highway capital for all those states with which it shares a border. The estimates indicate little evidence of beneficial spillovers; the point estimate is negative and significant. Of course, one possibility is that it is not the total of neighbors' highways that matters. Instead, productive spillovers may hinge on the distribution as well. Hence, in column (3) we present analogous estimates using the average of neighbors' highway capital stocks, with little effect on the basic results. Finally, in column (4) we employ 
a weighted-average of neighbors' state highways. We choose the weight for each neighboring state to be inversely proportional to the share of that state in the geographic area of all neighbors, a scheme designed to capture the notion that the same amount of highway capital will be more productive to one's neighbors if spread out over a small geographic area than if spread out over a large area. As appealing as this notion may be, a quick look at column (4) verifies it has little effect on the basic character of the results.

We stressed above the need to control for unobserved state-specific components of the error structure. In panel (b) of Table 4.1 we complete our preliminary look at the data by repeating our analysis using data entered in long differences to achieve this purpose. As before, the first column presents the estimates of a basic production function that excludes any measure of neighbors' highway capital. The estimated coefficient on own-state highways is 0.00724 and imprecisely estimated. The absence of productivity effects implied by this estimate echoes the findings of Holtz-Eakin [forthcoming] or Hulten and Schwab [1991]. Turning to the remainder of the columns, the evidence indicates little in the way of productivity spillovers as the point estimates are negative and insignificant.

To summarize, our preliminary regressions suggest little empirical support for the notion that public infrastructure - even state highways - have significant cross-state effects on output and productivity. The estimates in Table 4.1, however, restrict the effects to the first "ring" of neighboring states, which may be misleading.

Table 4.2 contains our estimates of the full spillover model, including differences to control for state effects (equation (3.2)). The columns correspond to the alternative measures of neighbors' highways introduced in Table 4.1.1 Begin with column (1) of panel (a) at the top of the table. As shown, the estimated elasticities with respect to labor and capital are 0.62 
and 0.42 , respectively. Both are precisely estimated. In contrast, both the estimated elasticity of output with respect to effective highways $\left(\beta_{3}=-0.022\right)$ and the spillover rate $(\delta=-0.15)$ are negative and insignificant. For our purposes, the latter result is the most notable. Moreover, the basic pattern of the results is repeated in the latter two columns of panel (a). Only in column (2) is the estimated value of $\delta$ positive; the value of 0.049 indicates that roughly five percent of the highway network in neighboring states augments the effective stock of state highways in each state. However, none of the estimates is statistically significant.

Panel (b) displays a final set of estimates. In principle, at least, our estimates of the spillover parameter may be sensitive to the presence of spatial correlation in the error terms. That is, productivity spillovers could be masked by negatively correlated co-movements in output among adjacent states. ${ }^{12}$ The estimates presented in panel (b) of Table 4.2 derive from specifying first-order spatial autocorrelation among the residuals in our equations. ${ }^{13}$

As the table indicates, the estimates reveal a positive correlation among output in neighboring states, an intuitive result. However, specifying the error structure in this way does have a dramatic impact on our estimates of $\delta$. In each case our estimate is negative, and often implausibly large. Because the point estimates of $\beta_{3}$ remain insignificant, these estimates have little implication for output. Indeed, the primary value of this specification is to rule out large, positive spillovers that are concealed by residual spatial correlation in our data. ${ }^{14}$

\section{5. $\quad$ SUMMARY}

This note has explored the empirical foundations of interstate productivity spillovers from state highways. The notion that a state's effective stock of highways depends upon the provision of highways by its neighbors has an intuitive appeal. However, our point estimates 
of the parameters of the spillover process do not support this intuitive notion: none of the econometric analyses reported herein suggest important productivity spillovers. Thus, spillovers among states do not appear to be at the heart of recent findings of a large productivity impact from public capital.

Perhaps this is unsurprising. Gramlich [1990], for example, reports that even on major interstate highways most drivers are from within the state. Still, this paper has explored a limited number of econometric specifications, and further investigation may prove profitable. It is also likely that both the direct and spillover benefits differ significantly across industries. Hence a disaggregated analysis may be advantageous. 


\section{NOTES}

1. Not all regression studies imply large productivity effects; see, e.g., Holtz-Eakin [forthcoming]. Munnell [1992], and the response in Holtz-Eakin [1993b], provide a convenient summary of the empirical debate.

2. Holtz-Eakin [forthcoming] provides indirect evidence by examining explicitly the effects of aggregation on estimated coefficients. Our approach focuses directly on spillovers and uses a specific type of public capital (state highways) rather than examining total public capital.

3. In our data, "state highways" are those roads owned by the state government (including interstate highways), while "local roads" are owned by the local governments in each state. See Holtz-Eakin [1993a] for a discussion of the data.

4. The log-linear framework has been used by Munnell [1990], Holtz-Eakin [forthcoming] and others. Tests in Holtz-Eakin [forthcoming] indicate that it is not overly restrictive.

5. An alternative parameterization is to attach $\delta$ to the actual capital stock, rather than the effective stock. If so, (2.3) becomes:

$$
h_{s}^{e}=h_{s}+\delta \sum_{n=1}^{N_{s}} w_{n} h_{n}
$$

This has the effect of restricting the impact of state highways to the first "ring" of neighboring states. One may interpret our preliminary regression work (below) as stemming from such a specification.

6. We thank her for providing these data.

7. Holtz-Eakin [1993a] describes the construction of these data.

8. We also experimented with specifications that included the stock of non-highway infrastructure on the right side. The coefficient of this variable is statistically insignificant and has little impact on the other estimates.

9. The test statistic, 60.2 , is distributed as a chi-square with 60 degrees of freedom. The VAR permits time-varying coefficients and includes time dummy variables.

10. Recall that these regressions are consistent with the specification discussed in note 5 . 
11. We also estimated the full spillover model in levels, thus ignoring state effects. In general, these results have the same character as the preliminary regressions in Table 4.1; i.e., a positive and significant coefficient on effective highways, but a negative (and often significant) spillover parameter.

12. In addition, Case, Hines, and Rosen [1993] demonstrate that state fiscal policies are geographically correlated. This specification controls for any endogenous element in the state-to-state pattern of highway capital.

13. See Cliff and Ord [1981]. We require a weighting matrix to implement the spatial correlation correction. Following the guidance of Kelejian and Robinson [1993], we use weights of $1 / N_{s}$, where $N_{s}$ is the number of neighboring states, for neighboring states, and zero for states that are not neighbors.

14. We conducted two other exercises to examine the robustness of our results. First, we imposed the constraint that our estimated production functions satisfy constant returns to scale in either: (i) all inputs, or (ii) private sector inputs. The estimates of $\delta$ were not sensitive to these restrictions. Also, we ignored the autocorrelated structure of our differenced error terms. Again, our results were little changed. 


\section{REFERENCES}

Aschauer, D., "Is Public Expenditure Productive?" Journal of Monetary Economics, 23, March 1989, pp. 177-200.

Case, A., J. Hines, and H. S. Rosen, "Budget Spillovers and Fiscal Policy Interdependence: Evidence from the States," Journal of Public Economics, 52, 1993, pp. 285-307.

Cliff, A., and J. Ord, Spatial Process: Models and Applications, London: Pion Limited, 1981.

Gramlich, E., A Guide to Benefit-Cost Analysis. Prentice-Hall Publishing, 1990.

Holtz-Eakin, D., "State-Specific Estimates of State and Local Government Capital," Regional Science and Urban Economics, Vol. 23, No. 2, April 1993a, pp. 185-210.

Holtz-Eakin, D., "Comment on Alicia Munnell," Journal of Economic Perspectives, Fall 1993b, pp. 231-234.

Holtz-Eakin, D., "Public Sector Capital and the Productivity Puzzle," Review of Economics and Statistics, forthcoming.

Holtz-Eakin, D., W. Newey, and H. Rosen, "Estimating Vector Autoregressions with Panel Data," Econometrica, Vol. 56, November 1988, pp. 1371-1396.

Hulten, C. and R. Schwab, "Public Capital Formation and the Growth of Regional Manufacturing Industries," National Tax Journal, December 1991, pp. 121-134.

Kelejian, H. and D. Robinson, "Spatial Correlation: The Cliff and Ord Model and a Suggested Alternative," New Directions in Spatial Econometrics, forthcoming.

Munnell, A., "Why Has Productivity Growth Declined? Productivity and Public Investment," New England Economic Review, January/February 1990a, pp. 3-22.

Munnell, A., "How Does Public Infrastructure Affect Regional Economic Performance?" in A. Munnell (ed.), Is There a Shortfall in Public Capital Investment? Boston: Federal Reserve Bank of Boston, 1990b.

Munnell, A., "Infrastructure Investment and Economic Growth," Journal of Economic Perspectives, Fall 1992, pp. 189-198. 
TABLE 3.1

Descriptive Statistics

(a) Levels ${ }^{\mathrm{a}}$

\begin{tabular}{|c|c|c|c|}
\hline Mean & $\begin{array}{c}\text { Standard } \\
\text { Deviation } \\
\end{array}$ & Minimum & Maximum \\
\hline 8.45 & 0.755 & 7.02 & 10.1 \\
\hline 10.4 & 1.03 & 8.25 & 12.9 \\
\hline 10.6 & 0.926 & 8.31 & 12.8 \\
\hline 13.7 & 1.04 & 11.4 & 16.1 \\
\hline
\end{tabular}

aata cover 1969-1986. Yearly data for each variable is measured in logarithms.

(b) Differences ${ }^{\mathrm{b}}$

\begin{tabular}{|c|c|c|c|}
\hline Mean & $\begin{array}{c}\text { Standard } \\
\text { Deviation } \\
\end{array}$ & Minimum & Maximu \\
\hline 0.246 & 0.136 & -0.135 & 0.735 \\
\hline 0.336 & 0.187 & -0.0289 & 0.968 \\
\hline 0.389 & 0.143 & 0.0258 & 0.904 \\
\hline 0.278 & 0.185 & -0.0692 & 0.943 \\
\hline
\end{tabular}

${ }^{b}$ Data cover 1975-1986. Yearly data for each variable is measured in logarithms and computed as the difference from the (logarithmic) value for 1969. See text for discussion. 
TABLE 4.1

Preliminary Regression Analysis

(a) Levels*

\begin{tabular}{|c|c|c|c|c|}
\hline & $\begin{array}{c}(1) \\
\text { Basic }\end{array}$ & $\begin{array}{l}(2) \\
\text { Total }\end{array}$ & $\begin{array}{c}\text { (3) } \\
\text { Average } \\
\end{array}$ & $\begin{array}{c}(4) \\
\text { Weighted }\end{array}$ \\
\hline Labor & $\begin{array}{c}0.608 \\
(0.0102)\end{array}$ & $\begin{array}{c}0.602 \\
(0.0104)\end{array}$ & $\begin{array}{c}0.619 \\
(0.0102)\end{array}$ & $\begin{array}{c}0.614 \\
(0.00954)\end{array}$ \\
\hline Capital & $\begin{array}{l}0.406 \\
(0.0122)\end{array}$ & $\begin{array}{c}0.409 \\
(0.0123)\end{array}$ & $\begin{array}{c}0.396 \\
(0.0122)\end{array}$ & $\begin{array}{c}0.416 \\
(0.0115)\end{array}$ \\
\hline Own Highways & $\begin{array}{c}0.0476 \\
(0.0167)\end{array}$ & $\begin{array}{c}0.0536 \\
(0.0168)\end{array}$ & $\begin{array}{c}0.0536 \\
(0.0165)\end{array}$ & $\begin{array}{c}0.0367 \\
(0.0156)\end{array}$ \\
\hline Neighbor's Highway & -- & $\begin{array}{c}-0.000712 \\
(0.000274)\end{array}$ & $\begin{array}{l}-0.0327 \\
(0.00648)\end{array}$ & $\begin{array}{l}-0.0753 \\
(0.00693)\end{array}$ \\
\hline
\end{tabular}

(b) Differences*

(1)

\begin{tabular}{c} 
Basic \\
\hline 0.580 \\
$(0.0251)$
\end{tabular}

Capital

Own Highways

Neighbor's Highway

Labor

$$
0.485
$$

(2)

$\frac{\text { Total }}{0.580}$

(3)

$\begin{array}{ccc}\text { Average } & & \text { Weighted } \\ \begin{array}{c}0.580 \\ (0.0252)\end{array} & & 0.580 \\ 0.0253)\end{array}$

0.485

(0.0388)

0.485

(0.0391)

0.484

$(0.0389)$

$-0.00655$

$(0.0262)$

$-0.000485$

$(0.00626)$
$-0.00704$

(0.0276)

$-0.0108$

$(0.0287)$

$-0.000711$

$(0.0444)$

\footnotetext{
"Total" = sum of neighboring states' highways; "Average" = average of neighboring states' highways; "Weighted" = weighted average of neighboring states' highways, where weights are inversely proportional to area of neighboring states. All regressions include an intercept and year dummy variables. Standard errors are shown in parentheses.
} 
TABLE 4.2

Estimates of Spillover Model

(a) No Correlation Correction*

\begin{tabular}{|c|c|c|c|}
\hline & $\begin{array}{c}\text { (1) } \\
\text { Total }\end{array}$ & $\begin{array}{c}(2) \\
\text { Average }\end{array}$ & $\begin{array}{c}(3) \\
\text { Weighted } \\
\end{array}$ \\
\hline Labor $\left(\beta_{l}\right)$ & $\begin{array}{c}0.624 \\
(0.0256)\end{array}$ & $\begin{array}{c}0.624 \\
(0.0233)\end{array}$ & $\begin{array}{c}0.624 \\
(0.0263)\end{array}$ \\
\hline Capital $\left(\beta_{o}\right)$ & $\begin{array}{c}0.415 \\
(0.0304)\end{array}$ & $\begin{array}{c}0.414 \\
(0.0300)\end{array}$ & $\begin{array}{c}0.414 \\
(0.0300)\end{array}$ \\
\hline Effective Highways $\left(\beta_{3}\right)$ & $\begin{array}{l}-0.0222 \\
(0.0249)\end{array}$ & $\begin{array}{l}-0.0191 \\
(0.0238)\end{array}$ & $\begin{array}{l}-0.0206 \\
(0.0301)\end{array}$ \\
\hline Spillover $(\delta)$ & $\begin{array}{l}-0.148 \\
(0.0352)\end{array}$ & $\begin{array}{c}0.0489 \\
(0.122)\end{array}$ & $\begin{array}{l}-0.215 \\
(0.152)\end{array}$ \\
\hline
\end{tabular}

(b) Spatial Correlation Correction*

\begin{tabular}{|c|c|c|c|}
\hline & $\begin{array}{c}\text { (1) } \\
\text { Total }\end{array}$ & $\begin{array}{c}(2) \\
\text { Average }\end{array}$ & $\begin{array}{c}(3) \\
\text { Weighted }\end{array}$ \\
\hline Labor $\left(\beta_{1}\right)$ & $\begin{array}{c}0.682 \\
(0.0346)\end{array}$ & $\begin{array}{c}0.679 \\
(0.0321)\end{array}$ & $\begin{array}{c}0.661 \\
(0.0313)\end{array}$ \\
\hline Capital $\left(\beta_{2}\right)$ & $\begin{array}{c}0.263 \\
(0.0390)\end{array}$ & $\begin{array}{c}0.236 \\
(0.0394)\end{array}$ & $\begin{array}{c}0.267 \\
(0.0392)\end{array}$ \\
\hline Effective Highways $\left(\beta_{3}\right)$ & $\begin{array}{l}-0.0077 \\
(0.0078)\end{array}$ & $\begin{array}{c}0.0164 \\
(0.0131)\end{array}$ & $\begin{array}{c}0.0139 \\
(0.058)\end{array}$ \\
\hline Spillover $(\delta)$ & $\begin{array}{l}-1.710 \\
(0.0306)\end{array}$ & $\begin{array}{l}-1.29 \\
(0.0851)\end{array}$ & $\begin{array}{l}-1.65 \\
(0.0262)\end{array}$ \\
\hline Spatial Correlation $(\rho)$ & $\begin{array}{c}0.151 \\
(0.016)\end{array}$ & $\begin{array}{c}0.728 \\
(0.0615)\end{array}$ & $\begin{array}{c}0.626 \\
(0.0604)\end{array}$ \\
\hline
\end{tabular}

\footnotetext{
" "Total" = sum of neighboring states' highways; "Average" = average of neighboring states' highways; "Weighted" = weighted average of neighboring states' highways, where weights are inversely proportional of area of neighboring state. All regressions include an intercept and year dummy variables. Standard errors are shown in parentheses.
} 